\title{
Mass developments of a small sized ecotype of Arthrospira fusiformis in Lake Oloidien, Kenya, a new feeding ground for Lesser Flamingos in East Africa
}

\author{
Lothar KRIENItZ $^{1 *}$, Pawan K. DADHEECH ${ }^{1,2,3}$ \& Kiplagat KotuT ${ }^{4}$
}

\author{
${ }^{1}$ Leibniz-Institute of Freshwater Ecology and Inland Fisheries, Alte Fischerhütte 2, D-16775 Stechlin, Germany; * \\ Corresponding author e-mail: krie@igb-berlin.de \\ ${ }^{2}$ Central University of Rajasthan, Department of Microbiology, Bandarsindri 305801, Kishangargh, India \\ ${ }^{3}$ Government College, Department of Botany, Ajmer 305001, Rajasthan, India \\ ${ }^{4}$ Embu University College, P.O. Box 6-60100 Embu, Kenya
}

\begin{abstract}
The Lesser Flamingos constantly commute between the soda lakes of East Africa in search of food. Their preferred food, the cyanobacterium Arthrospira fusiformis, usually establishes dense populations in saline-alkaline habitats. However, the algal food resources are not stable and crash unexpectedly from time to time. Hence any site that provides food in suitable quality and quantity makes a valuable contribution to the survival of these nearly endangered birds. This paper reports on the development of a new feeding ground for the Lesser Flamingos; Lake Oloidien, a former bay of the freshwater lake Naivasha. Phytoplankton succession and biomass, salinity and flamingo numbers were analysed over the period 2001-2013. As a result of a progressive increase in salinity to values of between 3 and 6 ppt, Oloidien has since 2006 hosted dense blooms of a small sized ecotype of $A$. fusiformis. Molecular phylogenetic analyses using the $16 \mathrm{~S}-23 \mathrm{~S}$ internal transcribed spacer (ITS) and partial sequences of the beta and alpha subunits including intergenic spacer ( $c p c$ BA-IGS) of the phycocyanin operon confirmed that a field clone and one isolated strain of Arthrospira from Lake Oloidien was similar to the strains in other soda lakes of Kenya. PCR-based results confirmed the non-toxic character of the isolated Arthrospira strain. The biomass of Arthrospira in the whole lake ranged from 236 to $301 \mathrm{t}$ dry weight in the phase when more than 100,000 flamingos were present (2006-2012). Based on the biomass of Arthrospira present, the carrying capacity of Lake Oloidien was calculated to be 150,000-250,000 Lesser Flamingos. In the phase of low flamingo numbers (2013), the biomass of Arthrospira in the lake rose to a value of $922 \mathrm{t}$.
\end{abstract}

Key words: Arthrospira; cyanobacteria; Lake Naivasha; Lake Oloidien; Lesser Flamingo; salinity

\section{INTRODUCTION}

The African saline alkaline lakes are hosts to two species of flamingos, the Greater Flamingo (Phoenicopterus roseus Pallas) and the Lesser Flamingo (Phoeniconaias minor Saint Hilaire). The two flamingo species differ in their food preference. Whereas the Greater Flamingo is a generalist that consumes small planktonic and benthic animals such as molluscs and arthropods, as well as mud and algae, the Lesser Flamingo is highly specialised as it depends on cyanobacteria and algae (JENKIN 1957; BRown 1959). Its preferred food is the cyanobacterium Arthrospira fusiformis (WoRONICHIN) KoMÁReK et J.W.G. LUND (often erroneously named as "Spirulina") (VARESCHI 1978). However, this algal food resource is not stable and crashes periodically (VARESCHI \& JACOBS 1985). Alternatively, Lesser Flamingos can feed on benthic diatoms and other eukaryotic algae. However, the grow rate and available biomass of these alternative food sources are much lower (Tuite 1981, 2000). Lesser Flamingos are mainly distributed in the soda lakes of East Africa, where about 2 million individuals of this enigmatic bird have been counted (ChILDRESS et al. 2008). Rising demographic pressure in the lakes' catchments has led to an accelerated degradation of the soda lakes. The consequence of these changes has been the alteration of the feeding grounds of Lesser Flamingo leading to a decline in the amount of food cyanobacteria of high nutritional value (KRIENITZ \& Kотит 2010). The special diet requirement and the need for undisturbed breeding habitats have made the Lesser Flamingo very sensitive to environmental changes. The only site in East Africa where this bird can breed successfully is Lake Natron in Tanzania. In its search for adequate food and suitable breeding places, the Lesser Flamingos exhibit an unsettled behaviour. Satellite tracking of flamingos fitted with transmitters in 2001 and 2002 showed that the longest distance made by one of the flamingos in a period of 15 months was $7,870 \mathrm{~km}$. In this period the flamingo made a total of 70 stopovers at 11 different lakes of East Africa (Childoress et al. 2006).

The major threats to the survival of Lesser Flamingos are the loss or deterioration of their unique habitats. In the red list of the International Union for the Conservation of Nature (IUCN), this species is 
classified as nearly threatened. An International Single Species Action Plan for Conservation of the Lesser Flamingo was established to protect this character bird of harsh soda lakes (CHILDRESS et al. 2008).

In this paper, we report on the development of a new feeding ground for Lesser Flamingos; Lake Oloidien, a former bay of Lake Naivasha in Kenya. The negative effects of overexploitation and degradation of the Lake Naivasha freshwater ecosystem (HARPER et al. 2002, 2011), has been accompanied by a positive development: a flamingo-lake was born (Fig. 1). The ambivalent development characterized by increasing salinity and a switch in the phytoplankton composition created favourable conditions for the flamingos (HARPER et al. 2006; Krienitz \& KotUT 2010; KRIENITZ et al. 2013). The focus of this study was the description and characterization of the food source and its suitability for Lesser Flamingos in Lake Oloidien. In this paper, the carrying capacity of the lake was computed and the findings used to evaluate whether the estimated high numbers of flamingos could overexploit the Arthrospira food resource in the lake. Molecular analyses were carried out to characterize the phylogenetic position of the Arthrospira population from Oloidien and its possible toxicity in comparison to other flamingo lakes in the region.

\section{Material and Methods}

Study site, sampling and microscopic studies of the phytoplankton. Lake Oloidien is located in the Great African Rift Valley next to Lake Naivasha, about $80 \mathrm{~km}$ North of Nairobi at an altitude of $1890 \mathrm{~m}$ above sea level (Fig. 2). Paleolimnological studies covering a time span of $\sim 1870$ - 1991 revealed that the water level of the lake fluctuated between 19 and $4 \mathrm{~m}$ while conductivity varied between $\sim 250$ and 14,000 $\mu \mathrm{S} . \mathrm{cm}^{-1}$ (Verschuren et al. 2000). Consequently, lakes Naivasha and Oloidien experienced periods of being one or separate water bodies. The present situation dates back to the 1980 s when decreasing lake levels led to a separation of Lake Oloidien from Lake Naivasha. The conductivity at this time was $660 \mu \mathrm{S}$ (KalfF \& Watson 1986). In the period 2001-2005, a conductivity of 3890 to $5270 \mu \mathrm{S} . \mathrm{cm}^{-1}$ was measured (BALLOT et al. 2009). The lake has no surface inflow and no surface outlet. At present, the endorheic basin has a surface area of about 450 ha and a maximum depth of $7 \mathrm{~m}$. The basin of Lake Oloidien is a caldera of a crater with the shape of a truncated cone. Based on its morphometric features, we calculated its volume to be $1.26 \times 10^{7} \mathrm{~m}^{3}$. The annual rainfall in this area is $500-700 \mathrm{~mm}$ and is the main source of water. Lake Oloidien is highly eutrophic with total phosphorus and total nitrogen values of between 0.4 and $1.0 \mathrm{mg} . \mathrm{1}^{-1}$, and 0.9 and $6.3 \mathrm{mg} . \mathrm{l}^{-1}$ respectively (BALLOT et al. 2009; our own measurements). The $\mathrm{pH}$ values increased from 9.3 at the beginning of the study to $10.2-10.4$ in the last five years.

The main sampling point (1) at Oloidien (Fig. 3) is located at the western shore near the village of Kongoni

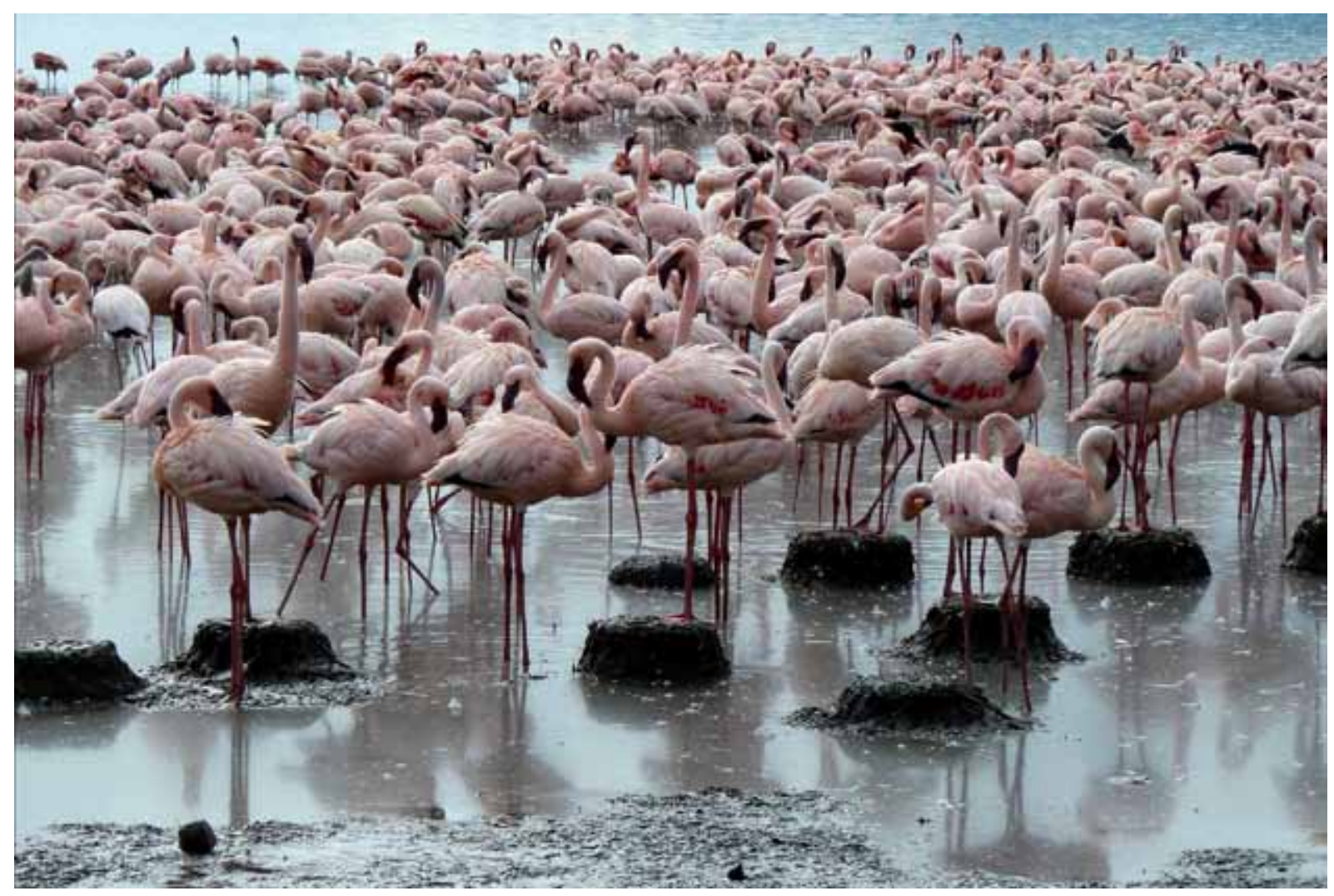

Fig. 1. Lesser Flamingos at Lake Oloidien. Although the birds were building nests, breeding was not possible because of disturbance by humans and predators. 
(00 $\left.49^{\prime} 00^{\prime \prime} \mathrm{S}, \quad 36^{\circ} 15^{\prime} 50^{\prime \prime} \mathrm{E}\right)$. During the period 2001 - 2013, 21 sampling trips were carried out at irregular intervals. The samples were taken from a depth of about $10 \mathrm{~cm}$ below the water surface and fixed with Lugol's solution for phytoplankton counting. Water samples for morphological studies were concentrated with a plankton net of $25 \mu \mathrm{m}$ mesh size and fixed with formaldehyde. During the sampling expeditions conducted in April 2012, November 2012, and January 2013, phytoplankton samples were also collected from eight different sampling points in addition to the sample from the main sampling point (Fig. 3 ). Samples were drawn from different depths $(0,2,4$, and 6 $\mathrm{m})$ using a Ruttner sampler. All the samples were counted in sedimentation chambers (Hydro-Bios Apparatebau GmbH, Kiel, Germany) under an inverted microscope Eclipse TS 100 (Nikon Corporation, Tokyo, Japan) following the method of UTERMÖHL (1958). The phytoplankton biomass (fresh weight, FW) was calculated by geometric approximations using the computerized counting programme OPTICOUNT (OpticounT 2008). The specific density of phytoplankton cells was taken as $1 \mathrm{~g} . \mathrm{cm}^{-3}$. Phytoplankton was photographically documented under a Nikon Eclipse E 600 light microscope using a Nikon digital camera DS-Fil, and Nikon software NIS-Elements D (Nikon Corporation, Tokyo, Japan). The size and morphology of Arthrospira from Oloidien was compared with those from lakes Nakuru and Bogoria. In addition to FW measurement in Lake Oloidien, we also computed dry weights (DW) of Arthrospira using samples collected in the last ten sampling trips and carried out in the period 2006-2013 when Arthrospira was the dominant phytoplankton. For this purpose, $100 \mathrm{ml}$ of a fresh water sample was filtered through pre-weighed glass fibre filters (Whatman GF/C, Whatman International Ltd Maidstone, England) in triplicate after which the filters were dried. After drying, the filters with samples were weighed again and the DW of the phytoplankton in $100 \mathrm{ml}$ of sample computed. A polycarbonate filter holder SM 16510 (Sartorius AG, Göttingen, Germany) and a manual vacuum pump VacuMan (Bürkle GmbH, Bad Bellingen, Germany) were used as filtration apparatus in the field. For the molecular analyses of field samples, 11 of the fresh sample was filtered using membrane filters with a pore-size of $0.6 \mu \mathrm{m}$ (Schleicher \& Schuell GmbH, Dassel, Germany). The salinity was measured at each sampling date using a WTW Multiline P4 meter (Wissenschaftlich Technische Werkstätten Weilheim, Germany).

Estimation of flamingo numbers. A visual estimate of the number of flamingos was made and sorted into four categories $(>100,000,>20,000,20,000-10,000$, and $<1,000$ individuals). These rough estimates were carried out at strategic points at the lake shore and from the boat. In many cases, it was possible to adjust our estimates by comparing our observed findings with those of the boat guides (Oloidien Community Boats, members of the initiative "Friends of Flamingos").

Cultivation of Arthrospira. To establish clonal cultures of Arthrospira, single filaments from fresh field samples were isolated with a micro capillary tube and transferred into liquid modified Bourrelly medium (KrIENITZ \& WirTh 2006). The BourRelly medium without salt (B) was mixed with BOURRELLY medium with salt (BS) in distinct proportions to receive a range of salinity $(0,2,4,8,12$, and $16 \mathrm{ppt}$ ). The $\mathrm{BS}$ medium contained $0.3 \mathrm{~g} \mathrm{Na}_{2} \mathrm{CO}_{3}$ and $15 \mathrm{~g}$

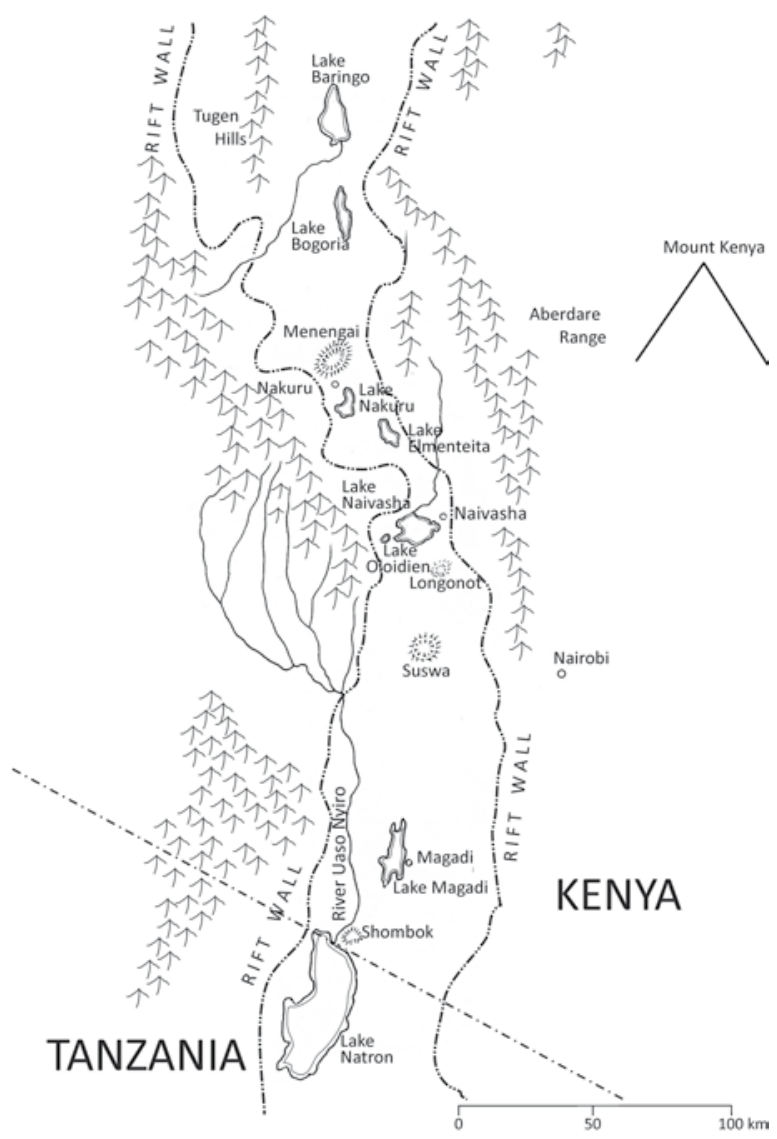

Fig. 2. Map showing the Rift Valles lakes in Kenya, modified from Brown (1959).

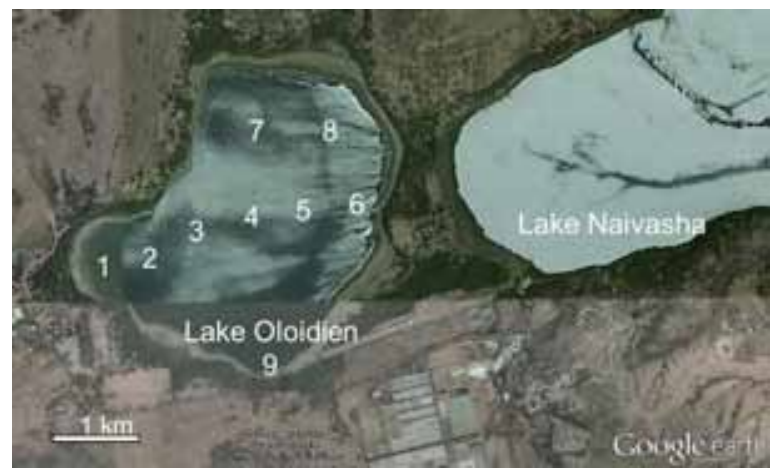

Fig. 3. Map taken from Google Earth showing Lake Oloidien and the sampling sites.

$\mathrm{NaCl}$ per litre. The cyanobacterial suspensions were grown in $100 \mathrm{ml}$ Erlenmeyer flasks at room temperature $(23 \pm 2$ ${ }^{\circ} \mathrm{C}$ ) under a $14 / 10$ light/dark regime. The strains isolated by LK were deposited in the algal strain collection of the Leibniz-Institute of Freshwater Ecology and Inland Fisheries at Stechlin. The strain KR2012/1 was used to test the growth at different salinities and molecular studies.

Molecular studies. The collected field samples were scrubbed from dried filter with a sterile scalpel. The genomic DNA of the field sample and the isolated strain KR2012/1 of Arthrospira was extracted using Dynabeads DNA DIRECT 


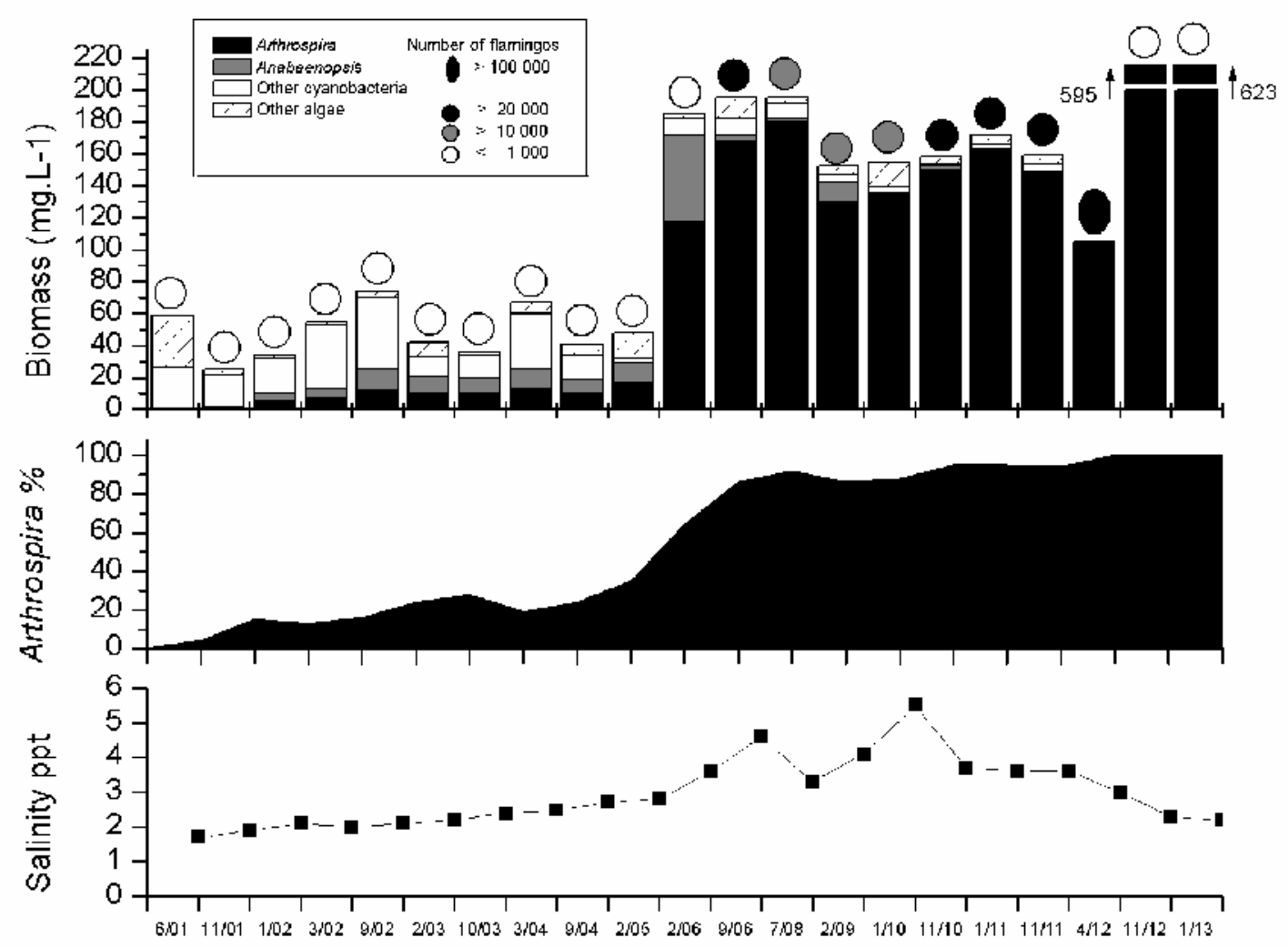

Sampling date

Fig. 4. Phytoplankton biomass (FW), succession of main phytoplankton groups, number of flamingos, percentage contribution of Arthrospira to total phytoplankton biomass, and salinity in Lake Oloidien during the period 2001-2013.

System I (Invitrogen/Dyanl Biotech, Oslo, Norway) following the steps outlined in the manufacture's manual. The two genetic loci (ITS and $c p c$ BA-IGS) were employed for both cases as these markers are considered the most suitable to characterize Arthrospira strains (BAURAIN et al. 2002; DADHEECH et al. 2010). The polymerase chain reaction (PCR) of ITS region and $c p c$ BA-IGS locus was performed in a Peltier Thermal Cycler PTC 200 (MJ Research Inc., San Francisco, USA) using PCR cocktail and protocol as previously described (DADHEECH et al. 2010). The primers 16 S3'F and B235'R (BAURAIN et al. 2002) were used to amplify ITS region while the primers cpc_arF and cpc_arR (BALLOT et al. 2004) were used to obtain partial sequence of $c p c \mathrm{BA}-\mathrm{IGS}$. PCR products of the ITS region and $c p c \mathrm{BA}-$ IGS locus were purified through Qiaquick PCR purification columns (Qiagen, Hilden, Germany). The purified products of field sample were cloned using the Zero Blunt ${ }^{\circledR}$ Topo ${ }^{\circledR}$ PCR cloning kit (Invitrogen, Germany) according to manufacturer's instructions. Positive colonies were selected and amplified with PCR and then sequenced to retrieve the sequence of ITS region and $c p c \mathrm{BA}-\mathrm{IGS}$ locus. The clones of ITS and $c p c \mathrm{BA}-\mathrm{IGS}$ were designated as Olo_arthro_its and Olo_arthro_cpc respectively. Both strands of purified DNA (ITS and $c p c \mathrm{BA}-\mathrm{IGS}$ ) were sequenced with the same primers used for the PCR on ABI 3100 Avant Genetic Analyzer (Applied Biosystem, Applera, Darmstadt, Germany).

The genetic potential of the investigated Arthrospira sp. strain (KR2012/1) to produce a variety of cyanotoxins was assessed using different primer sets. The primers and PCR protocol for each genetic locus, HEPF/HEPR for microcystin/nodularin (JungBlut \& NeILAN 2006), FAA/
RAA for $m c y$ B (NeILAN et al. 1999), AnaC-genF/AnacCgenR for anacystin (RANTALA-Ylinen et al. 2011) and sxtA-F/sxtA-R for saxitoxin (AL-TeBRINEH et al. 2010) were employed for amplification.

The sequences of ITS and $c p c \mathrm{BA}-\mathrm{IGS}$ locus of Arthrospira particularly from Asian, African and Mexican origin were retrieved from nucleotide NCBI database and aligned with sequences obtained in present study using software MUSCLE (Edgar 2004). Alignment was checked visually using the Manual Sequence Alignment Editor, Align v05/2008 (Hepperle 2008). The phylogenetic trees were constructed by the maximum likelihood (ML) method using the program MEGA v5.0 (TAMURA et al. 2011) with default settings, Jukes-Cantor model of nucleotide. Confidence values for the edges of the maximum-likelihood tree were computed by bootstrapping of 1000 replications. The nucleotide sequences reported in this study have been deposited in the NCBI database under the GenBank accession number JX853612-JX853613 (ITS) and JX853614JX853615 (cpcBA-IGS).

\section{Results}

In the years 2001-2005, the number of flamingos at Oloidien was very low and never exceeded 1,000 individuals. In 2006, the situation changed dramatically. The number of flamingos increased from less than 1,000 in February to more than 20,000 in September 

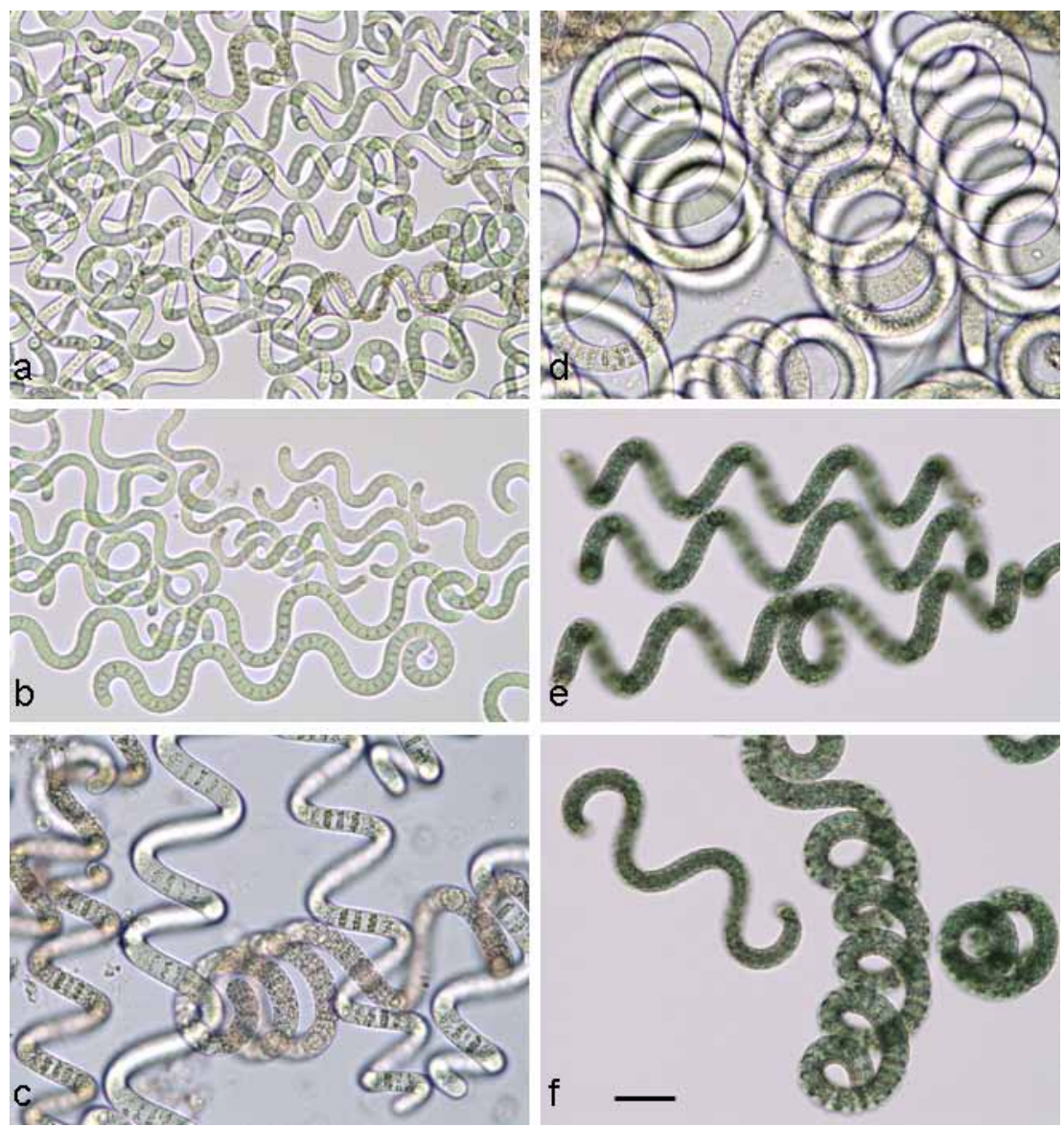

Fig. 5. Microphotographs of Arthrospira fusiformis; for direct comparison, all figures are provided with the same magnification. (a-d) field samples: (a, b) small sized ecotype from Lake Oloidien, (c) Lake Nakuru, (d) Lake Bogoria; (e, f) strain KR 2012/1 isolated from Lake Oloidien as small ecotype which grows in suspension cultures up to larger sized variants. Scale bar $30 \mu \mathrm{m}$.

2006 (Fig. 4). In the following years, the flamingo numbers fluctuated between 10,000 and 20,000 . Towards the end of 2010, the flamingos established a stable population of up to 50,000. In 2012, there was again an increase in the number of birds with more than 100,000 flamingos being observed. By April 2012, between 150,000 and 250,000 flamingos were recorded in Oloidien. In November 2012 and January 2013 , the number of flamingos decreased dramatically to only about 1000 .

The rise in flamingo numbers at Oloidien resulted from a shift in the phytoplankton community structure brought about by the considerable changes in water chemistry. Between 2001 and 2005, the water was moderately saline with a salinity of about 2 ppt. During this low salinity phase, the phytoplankton was dominated by coccoid green algae as well as coccoid and colonial cyanobacteria. The filamentous cyanobacterium Anabaenopsis was subdominant and reached its maximum in 2006 with densities of $50-$ $60 \mathrm{mg} \cdot \mathrm{l}^{-1}$. However, in 2006 the salinity level reached a value of more than 3 ppt. The attainment of this salinity level led to a massive growth of Arthrospira fusiformis, the favourite food for the Lesser Flamingo. Because of the long dry seasons in subsequent years, salinity increased reaching a maximum value of 5.5 ppt in January 2010. Although the heavy rains received in 2010/2011 diluted the water to salinity values of 3 ppt, Arthrospira development remained on the same high biomass level of more than $150 \mathrm{mg} . \mathrm{l}^{-1} \mathrm{FW}$ (Fig. 4). Even in November 2012 and January 2013, when heavy rains resulted in a drop in salinity to values of 2.3 and $2.2 \mathrm{ppm}$ respectively, phytoplankton dominance by Arthrospira remained at $100 \%$. Because of the extremely low numbers of flamingos, it was interesting to measure the phytoplankton biomass in this phase when the grazing pressure was insignificant. The Arthrospira biomass in Lake Oloidien rose to a maximum of $623 \mathrm{mg} \cdot \mathrm{l}^{-1}$ and was entirely made of small filament forms (Fig. 5a). The majority of filaments were 4-5 $\mu \mathrm{m}$ wide with a few being 6-8 $\mu \mathrm{m}$ wide. Filament lengths ranged from $60-100 \mu \mathrm{m}$ with $2-4$ coils. The few broader filaments had lengths of up to $200 \mu \mathrm{m}$ with 4-6 coils (Fig. 5b). We found only a few gas vesicles in the cells of the small filaments. Spiral diameter in each filament ranged from 25-40 $\mu \mathrm{m}$. Comparing the morphology of Arthrospira from Oloidien with that from the main flamingo lakes of the Kenyan Rift Valley, the form found in Oloidien was considerably smaller than the specimens from Lake Nakuru (Fig. 5c) 
(filaments 10-13 $\mu \mathrm{m} \mu \mathrm{m}$ wide and 150-300 $\mu \mathrm{m}$ long) and Lake Bogoria (Fig. 5d) (filaments 12-15 $\mu \mathrm{m}$ wide and up to $700 \mu \mathrm{m}$ long, with up to 20 coils). Many gas vesicles are visible in these large filaments. When grown in culture, the strains from Lake Oloidien, lost their small size and reached larger dimensions comparable to those measured in the field material of Nakuru and Bogoria (Fig. 5e, f) within 30 days of growth, even under a salinity of 2 ppt. Laboratory experiments on the biomass production of strain KR2012/1 under different salinity regimes resulted in a maximum yield at $8 \mathrm{ppt}$ salinity. At a salinity of 16 ppt, a considerably lower biomass production was observed while at a salinity of $0.1 \mathrm{ppt}$, very limited biomass production was recorded (Fig. 6).

The buoyancy behaviour of the Arthrospira forms from the three different lakes contrasted sharply. Depth samples drawn from different depths of the water column using a Ruttner sampler revealed that the small form in Oloidien was evenly distributed down the water column and did not show a dense accumulation on the upper layer of the water. In Lake Nakuru, we observed a moderate layering in the upper five centimetres while in Lake Bogoria, a strong accumulation of Arthrospira on the water surface was observed leading to dense paste-like scums of the cyanobacterium in the upper $1-2 \mathrm{~cm}$. This phenomenon could be attributed to the comparatively higher number of gas vesicles in the large filaments.

We obtained sequences of $411 \mathrm{bp}$ long for ITS region and of $489 \mathrm{bp}$ long for $c p c \mathrm{BA}-\mathrm{IGS}$ locus. The phylogenetic position of field clone and isolate (KR2012/1) were determined in ML trees of ITS and $c p c \mathrm{BA}-\mathrm{IGS}$ regions. For both loci, Arthrospira sequences of the same strain from different Kenyan, Indian and Mexican lakes were also compared to our sequences. The ITS and $c p c \mathrm{BA}-\mathrm{IGS}$ sequences of the field clone as well as the isolate occurred in the cluster comprising strains of Arthrospira from several Kenyan lakes (Fig. 7). PCR studies aimed at determining the cyanotoxin production potential by the Arthrospira isolate under investigation using several specific primer pairs did not lead to the amplification of any genetic locus responsible for the production of cyanotoxins (data not shown). Tests for the presence of microcystins and anatoxin-a confirmed the absence of toxins in a field sample collected on 21 November 2011 (Jutta Fastner, unpubl. data).

Biomass measurements established that 1 mg DW was equivalent to $8.5 \mathrm{mg} \mathrm{FW}$ as reported by VARESCHI (1982). The mean Arthrospira biomass obtained in the eight sampling trips carried out in the phase of high abundance of flamingos (September 2006-April 2012) was $153 \pm 21 \mathrm{mg} \cdot 1^{-1} \mathrm{FW}$ and $18.7 \pm$ $2.5 \mathrm{mg} . \mathrm{l}^{-1} \mathrm{DW}$ (standard deviation given) at the main sampling point. Arthrospira biomass measurements carried out in nine sampling points on 14 April 2012 and 24 April 2012 gave mean biomass values of $190 \pm$
$15 \mathrm{mg} . \mathrm{l}^{-1} \mathrm{FW}$ and $22.4 \pm 1.7 \mathrm{mg} . \mathrm{l}^{-1} \mathrm{DW}$ (14 April 2012) and $203 \pm 13 \mathrm{mg} . \mathrm{l}^{-1} \mathrm{FW}$ and $23.9 \pm 1.5 \mathrm{mg} . \mathrm{l}^{-1} \mathrm{DW}(24$ April 2012). As the Arthrospira biomass was found to be evenly distributed down the water column, the total DW for the whole lake was calculated to be $236 \mathrm{t}$ based on mean value for the period 2006-2012 and 301 t for 24 April 2012. In November 2012 and January 2013 when the number of flamingos dropped to about 1000 birds, the grazing pressure on the Arthrospira population became insignificant. During this period, the total biomass calculated for the whole lake rose a high of 880 t (November 2012) and 922 t (January 2013).

\section{Discussion}

Increase of flamingo numbers at Lake Oloidien The soda lakes in Kenya host the densest population of flamingos in East Africa. Although the number of birds in each lake varies widely, the total number sometimes rises to more than 2 million individuals (BROwN 1959; ChILDREss et al. 2008). Under favourable conditions, the main lakes of Nakuru, Bogoria and Elmenteita can accommodate about 1.5 million (BROWN 1959, VARESCHI 1978), 2 million (BRown 1959; HARPER et al. 2003), and 108,081 (OwINo et al. 2001) birds respectively. Twice a year, estimates of bird numbers in the lakes is carried out by ornithologists through an initiative of the African Waterfowl Census (Maina \& Kyungu 2009). By compiling the bird numbers simultaneously at all the main distribution areas, an overview of the total population density of a bird species and its trends can be established (NASIRwA et al. 2007). However, because of the itinerant behaviour of Lesser Flamingos, such a counting programme may not detect the peak numbers of flamingos at a given lake. Short term changes in population density are extremely difficult to determine and depend on randomly scheduled counting

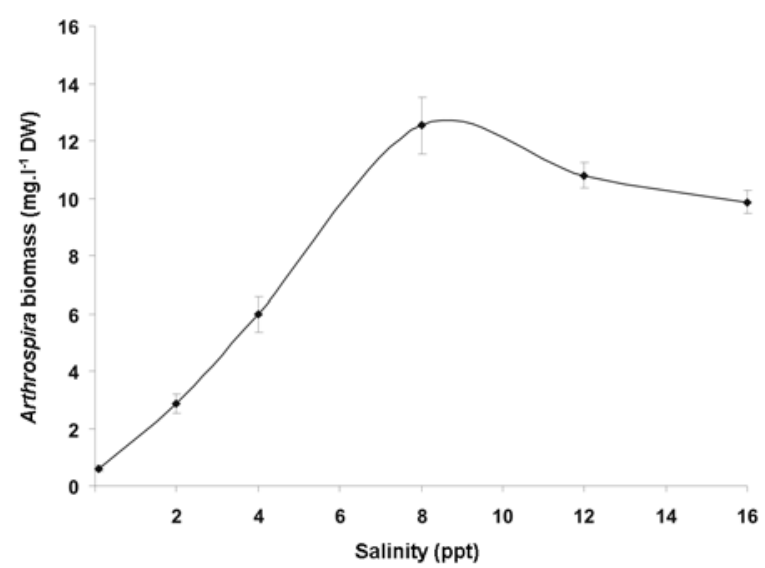

Fig. 6. Dry weight of Arthrospira fusiformis, strain KR 2012/1, under different salinity. 

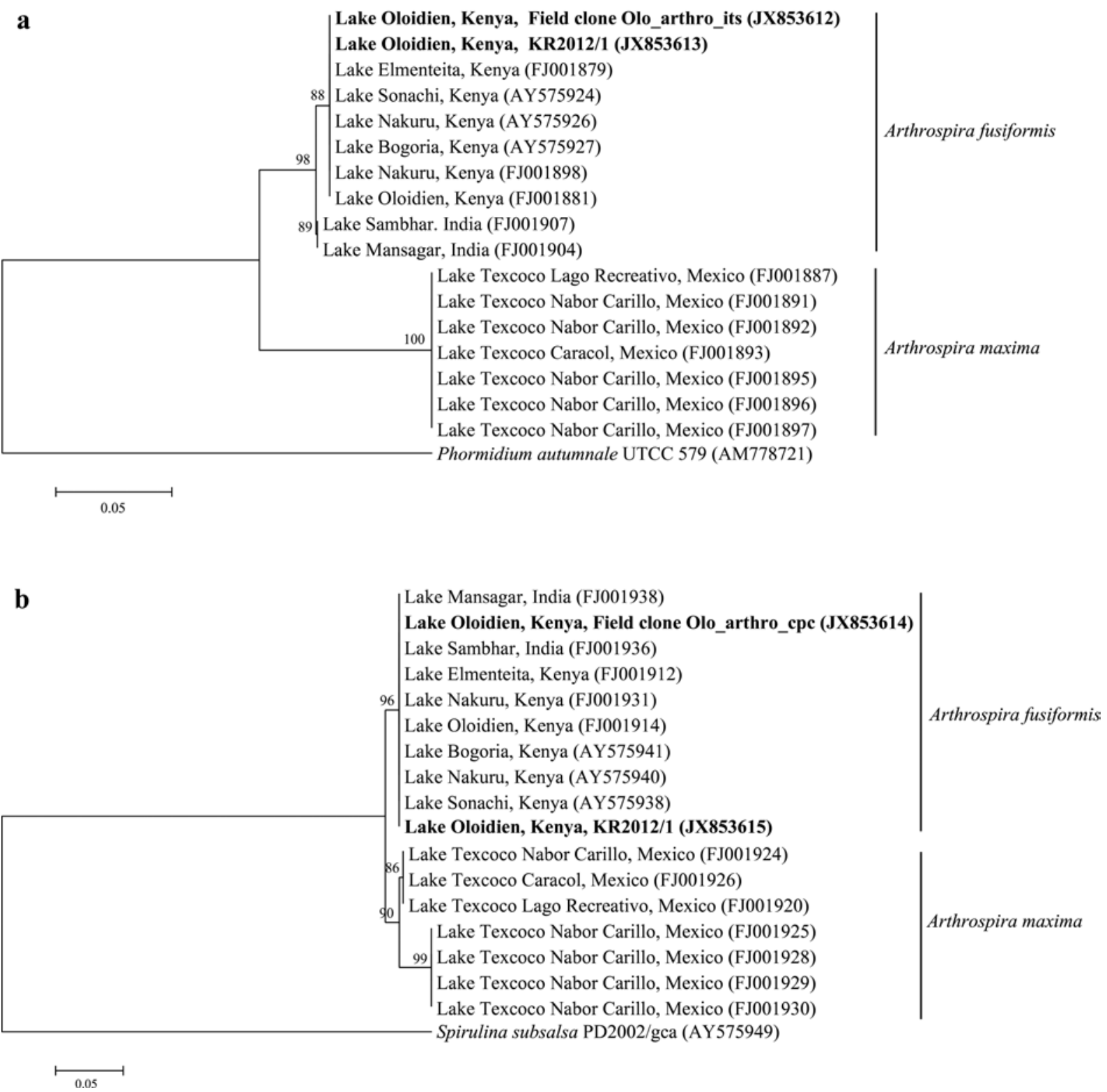

Fig. 7. (a) Maximum-likelihood phylogenetic tree based on ITS sequences of Arthrospira. Phormidium autumnale UTCC 579 was used as an outgroup. The tree was derived using Jukes-Cantor model. The numbers above branches indicate bootstrap support ( $>50 \%)$ from ML $(1,000)$ replicates. (b) Maximum-likelihood phylogenetic tree based on cpcBA-IGS sequences of Arthrospira. Spirulina subsalsa PD2002/gca was used as the outgroup. The tree was derived using Jukes-Cantor model. The numbers above branches indicate bootstrap support ( $>50 \%$ ) from ML $(1,000)$ replicates.

programmes. At the beginning of the massive flamingo establishment at Lake Oloidien in 2006, Earthwatch research teams gave an estimate of nearly a quarter of a million flamingos in October (Earthwatch Institute 2006). However, a month earlier, we had counted only about 20,000 flamingos. Members of the "Friends of Flamingos" group at Oloidien who undertake daily boat trips on the lake confirmed that during the phase of a rapid increase in flamingo numbers that begun in 2010, the counts have varied widely with daily fluctuations sometimes being by more than $50 \%$. The birders have reported that in January - March 2012, nearly one half of a million Lesser Flamingos collected their food from Lake Oloidien. Enthusiastic calculations posted in the internet for the same period have given values of about 1.5 millions birds at the lake (STANDARD MEDIA 2012). Our irregular observations over a period of 12 years have clearly demonstrated a progressive increase in numbers of Lesser Flamingos at Lake Oloidien with numbers varying between 100,000 and 250,000 individuals. Owing to an expected strong grazing pressure on the primary producers in the lake by the high numbers of flamingos, we characterized the quality and quantity of the food algae available. At the end of our observation period (November, 2012 and January 2013), the number of flamingos dropped drastically to only about 1000 individuals. It is suspected that they could have moved to Lake Natron for breeding (BBC 
NATURE 2012). We used this occasion when the grazing pressure was absent to quantify the food concentration.

\section{Characterization of the small type of} Arthrospira fusiformis from Lake Oloidien

Arthrospira fusiformis observed in Lake Oloidien belongs to the variety minor, which refers to populations of fine filaments $4-5 \mu \mathrm{m}$ in width ( $\mathrm{RiCH}$ 1932) and whose earlier designation was $A$. platensis (Nordstedt) Gomont, a synonym of $A$. fusiformis. RICH first reported the presence of var. minor in the Crater Lake. The Crater Lake Sonachi is located at a distance of only $3.7 \mathrm{~km}$ from Lake Oloidien. Interestingly, at the time of Rich's collection in 1929, water salinity in the Crater Lake was about 3 ppt (computed from conductivity data published by VERSCHUREN et al. 1999). Presently, the salinity of this lake is about $10 \mathrm{ppt}$ and its phytoplankton composition is dominated by the large size form of Arthrospira fusiformis (BALLOT et al. 2005). Generally, under field conditions, the small variety is rare. With the exception of its dominance in Lake Oloidien, the variety minor is rarely observed. We found it at a comparably high density at Kamfers Dam (South Africa), which has a similar salinity range of about 3 ppt (Lothar Krienitz, unpubl. results). Moreover, the small size variety of A. fusiformis has been reported to be a contaminant of outdoor mass cultivations of the "normal" form of Arthrospira (VONSHAK \& RichMOND 1988). Although the small sized variant of $A$. fusiformis has been found to be more sensitive to high ultraviolet radiation, this deficiency is usually compensated for by the lower cell buoyancy that results in a more-or-less uniform distribution within the water column. This reduces the risk associated with strong solar radiation on the water surface (GAO \& MA 2008). The uniform distribution of the small size Arthrospira in the water column was a consistent feature of Oloidien throughout the present study. In contrast, the large size form established dense surface scums in Bogoria. In Lake Nakuru, VARESCHI (1982) identified two different types of Arthrospira at different periods; a small size type (resembling the var. minor) that was uniformly distributed throughout the water column during phases of dense blooms and a large size type that establishes surface scums on the lake during phases of low phytoplankton density. He recognized two different taxa, spec. 1 and spec. 2. However, we were not able to corroborate this differentiation. Our growth experiments under different medium salt concentration revealed that the small size variant of Arthrospira does well under low to moderate salinity conditions. Data from past studies however suggest a high potential of Arthrospira to adapt to different salinities. Even under a salinity of more than $30 \mathrm{ppt}(>0.5 \mathrm{M})$, Arthrospira exhibited a strong growth performance after a time lag of several hours (VONSHAK et al. 1988).

Salinities of more than $8 \mathrm{ppt}$ induced an increase in filament size. Furthermore, molecular investigations confirmed that the small and large size forms of Arthrospira fusiformis from the soda lakes of East Africa are phylogenetically similar (DADHEECH et al. 2010). In this study, we confirmed these findings through molecular phylogenetic analyses of a field sample and the strain isolated from Lake Oloidien (KR2012/1). These results are in agreement with our previous observations on the remarkable conservation in sequences of ITS and $c p c$ BA-IGS loci and absence of habitat dependent phylogenetic grouping among Arthrospira strains (DADHEECH et al. 2010). Hence filament size has no taxonomic value and currently, the existence of the var. minor is doubtful. The populations of small size filaments of Arthrospira can be considered as an ecotype growing in alkaline waters of $<5 \mathrm{ppt}$ salinity. Furthermore, we did not detect potential cyanotoxin producing genes in the Arthrospira strain using different molecular markers. This finding reveals the non-toxic character of the strain (KR2012/1) isolated from Lake Oloidien.

\section{Arthrospira as a food resource for Lesser Flamingos at Lake Oloidien}

Does the small size of Arthrospira filaments in Lake Oloidien have an impact on food ingestion by Lesser Flamingos? The bill of Lesser Flamingo has fine lamellae, and these lamellae are equipped with rows of fringed platelets which have an average distance of 120 $\mu \mathrm{m}$. There are about 20 platelets. mm $^{-2}$ (JENKIN 1957). The efficiency of this filter apparatus depends on the size of food particles (VARESCHI 1978). Analysis of the stomach contents of Lesser Flamingos revealed that the smallest particles filtered in large quantities were pennate diatoms with a size range of 15-70 $\mu \mathrm{m}$, while the main food constituent was Arthrospira with a size range of 40-800 $\mu \mathrm{m}$ (JENKIN 1957). Hence the small size form of Arthrospira from Oloidien fits perfectly into the size range of food particles trapped by the filter apparatus of Lesser Flamingos.

According to BRown (1959) an adult flamingo with $1.8 \mathrm{~kg}$ weight has a minimum daily food requirement of about $180 \mathrm{~g} \mathrm{FW}(=21.2 \mathrm{~g} \mathrm{DW})$. Feeding experiments using caged Lesser Flamingos at Lake Nakuru in the early 1970s revealed that an adult bird must consume much more for its survival (VARESCHI, 1978). A Lesser Flamingo filters 301 of lake water to ingest $5.6 \mathrm{~g} \mathrm{DW}$ of Arthrospira per hour, which is equal to $72 \pm 6.5 \mathrm{~g}$ DW per day. The whole flamingo population of about 915,000 birds therefore extracted some $60 \mathrm{t}$ of food algal DW per day, representing 50\% $-94 \%$ of the daily primary production of the lake or $0.4-0.6 \%$ of the total algal biomass. We calculated a standing crop of Arthrospira in Lake Oloidien to be $236-301 \mathrm{t}$. Using a flamingo density estimate of 200,000 for Lake Oloidien, based on recent estimates, the birds can consume $14.4 \mathrm{t}$ per day. This is $4.8-6.1$ $\%$ of the standing crop. Hence theoretically, the 
flamingos can empty the lake of Arthrospira within 16-20 days. However, Arthrospira is known for its high growth rate. In culture, both the normal and the small size ecotypes have growth rates of about one doubling per day (GAO \& MA 2008). VonsHAK (1997) found doubling times of Arthrospira in culture of 11$20 \mathrm{~h}$ depending on salinity. However, the calculation of biomass production under field conditions in saline lakes is complicated by the multiple biotic and abiotic interferences (VARESCHI \& JACOBS 1985). In natural populations of Arthrospira in the soda lake Simbi, an increase of $0.5 \mathrm{mg} . \mathrm{l}^{-1} \mathrm{DW}$ per hour based on a standing crop of $100 \mathrm{mg} \cdot \mathrm{l}^{-1} \mathrm{DW}$ was measured (MeLACK 1979). Applying these findings, rough growth rate estimate for Oloidien of $0.1 \mathrm{mg} . \mathrm{l}^{-1} \mathrm{DW} \mathrm{h} \mathrm{h}^{-1}$ can be calculated based on a standing crop of $20 \mathrm{mg} .1^{-1} \mathrm{DW}$ and a vegetation time of $12 \mathrm{~h}$. This translates in to a daily production of $15.1 \mathrm{t}$ Arthrospira in the lake, which is only slightly more than the calculated bird consumption of $14.4 \mathrm{t}$ per day. However, we have to consider that the turnover rate can increase as a result of higher grazing pressure (VARESCHI 1978). In suspension with a lower algal density, the self-shading effects are reduced and this can lead to higher growth rates. Furthermore, the flamingos could utilize additional food resources such as diatoms from the mud and rotifers which occur in high densities in the plankton of Oloidien. Nevertheless, these calculations show that the carrying capacity for flamingos of Lake Oloidien falls in the range between 150,000 and 250,000 birds, hence the observed numbers at the lake did not result in the overexploitation of the food resource. Further investigations are, however, necessary to shed more light on energy flow in the lake including the role of other members of the food chain.

Still, one question on the critical concentration of food algal suspension necessary for normal feeding by flamingos remains unanswered. Based on feeding experiments, VARESCHI $(1978,1982)$ concluded that flamingos stopped feeding when the biomass of food fell below $100 \pm 5 \mathrm{mg} . \mathrm{l}^{-1} \mathrm{DW}$. He therefore concluded that the critical concentration of food algal suspensions necessary for normal feeding by flamingos is $100 \pm 5 \mathrm{mg} . \mathrm{l}^{-1} \mathrm{DW}$. We never observed a food algal concentration higher than this critical biomass in Oloidien. The highest value detected during our study was $25 \mathrm{mg} . \mathrm{l}^{-1} \mathrm{DW}$. However, the flamingos did not stop feeding. Comparing data from past studies after converting FW into DW, it is evident that the concentration of Arthrospira in the main flamingo lakes during the last decade has been below the critical value of $100 \mathrm{mg} . \mathrm{l}^{-1} \mathrm{DW}$ (BALLOT et al. 2004; Schagerl \& OduOR 2008; Krienitz \& Kotut 2010). It is therefore possible that the flamingos may have changed their feeding behaviour in response to the lower food concentration. An exception to this was Lake Bogoria, which occasionally had a high biomass of Arthrospira of about $100 \mathrm{mg} . \mathrm{l}^{-1}$ DW (BALlot et al.
2004; KAGGWA et al. 2012).

In the light of earlier studies that revealed the presence of cyanotoxins in samples from soda lakes of East Africa (CoDD et al. 2003; KRIENITZ et al. 2003; BALlot et al. 2004, 2005), it is important to note that no cyanotoxins were detected in the phytoplankton of Lake Oloidien, and even the search for toxin-genes in a field clone and two strains isolated turned negative. The emergence of Lake Oloidien as a new feeding habitat for the Lesser Flamingos could not have come at a better time as this took place when the Arthrospira populations at two major flamingo-lakes of Elmenteita and Nakuru collapsed in 2010 and 2011 respectively. Lake Oloidien, is a positive development in the history of the Lake Naivasha ecosystem, which has suffered a number of anthropogenic disturbances over the last few decades that include introduction of alien plant and animal species, excessive abstraction of lake water to support geothermal power industry, horticulture and water supply to increasing human settlements in the catchment area (HARPER et al. 2011). The Lesser Flamingos have therefore accepted Lake Oloidien as a new refugium and moved into the lake in high numbers.

ACKNowledgements

We thank the Government of Kenya for permission to carry out this research (No. MOEST 13/001/31 C 90, and NCST/RRI/12/1/ $\mathrm{BS} / 232$ ). We thank the Oloidien Community Boats, members of the initiative "Friends of Flamingos" for assistance in sampling and valuable discussions. PKD was supported by a fellowship of the Leibniz-Institute of Freshwater Ecology and Inland Fisheries. PKD is grateful to Department of Higher Education, Government of Rajasthan, India, for granting permission to carry out research work at IGB, Germany. We thank Monika Degebrodt, Monika Papke and Reingard Rossberg for technical support.

\section{REFERENCES}

Al-Tebrineh, J.; Mihali, T.K.; Pomati, F.\& Neilan, B.A. (2010): Detection of saxitoxin-producing cyanobacteria and Anabaena circinalis in environmental water blooms by quantitative PCR. Appl. - Environ. Microbiol. 76: 7836-7842.

Ballot, A.; Dadheech, P.K. \& Krienitz, L. (2004): Phylogenetic relationship of Arthrospira, Phormidium and Spirulina strains from Kenyan and Indian waterbodies. - Algological Studies 113: $37-56$.

Ballot, A.; Kotut, K.; Novelo, E. \& Krienttz, L. (2009): Changes of phytoplankton communities in Lakes Naivasha and Oloidien, examples of degradation and salinization of lakes in the Kenyan Rift Valley.Hydrobiologia 632: 359-363.

Ballot, A.; Krienitz, L.; Kotut, K.; Wiegand, C.; Metcalf, J.S.; Codd, G.A. \& Pflugmacher, S. (2004): Cyanobacteria and cyanobacterial toxins in three alkaline Rift Valley lakes of Kenya - Lakes Bogoria, Nakuru and Elmenteita. - J. Plankt. Res. 26: 925-35.

Ballot, A.; Krienitz, L.; Kotut, K.; Wiegand, C. \& Pflugmacher, S. (2005): Cyanobacteria and 
cyanobacterial toxins in the alkaline crater lakes Sonachi and Simbi, Kenya. - Harmful Algae 4: 139150.

Baurain, D.; Renquin, L.; Grubisic, S.; Scheldeman, P.; Belay, A. \& Wilmotte, A. (2002): Remarkable conservation of internally transcribed spacer sequences of Arthrospira ("Spirulina") (Cyanophyceae, Cyanobacteria) strains from four continents and of recent and 30-year-old dried samples from Africa. - J. Phycol. 38: 384-393.

BBC Nature (2012): Major flamingo breeding event begins on Lake Natron. http://www.bbc.co.uk/ nature/20271751 (accessed on 26.02.2013).

Brown, L. (1959): The Mystery of the Flamingos. - Country Life Ltd., London, 116 pp.

Childress, B.; Hughes, B.; Harper, D.; Van den Bossche, W.V.; Berthold, P. \& Querner, U. (2006): Satellite tracking documents the East African flyway and key site network of the Lesser Flamingo Phoenicopterus minor. - In: Boere, G.C.; Galbraith, C.A. \& Stroud, D.A. (eds): Waterbirds around the world. - pp. 234238, The Stationery Office, Edinburgh, UK.

Childress, B.; Nagy, S. \& Hughes, B. (Compilers) (2008): International single species action plan for the conservation of the Lesser Flamingo (Phoeniconaias minor). - In: CMS Technical Series No. 18. Agreement on the conservation of African-Eurasian Migratory Waterbirds (AEWA) Technical Series No. 34. - 59 pp., Bonn, Germany.

Codd, G.A.; Metcalf, J.S.; Morrison, L.F.; Krienitz, L.; Ballot, A.; Pflugmacher, S.; Wiegand, C. \& Koтuт, K. (2003): Susceptibility of flamingos to cyanobacterial toxins via feeding. - Vet. Rec. 152: $722-723$.

Dadheech, P.K.; Ballot, A.; Casper, P.; Kotut, K.; Novelo, E.; Lemma, B.; Pröschold, T. \& Krienitz, L. (2010): Phylogenetic relationship and divergence among planktonic strains of Arthrospira (Oscillatoriales, Cyanobacteria) of African, Asian and American origin deduced by $16 \mathrm{~S}-23 \mathrm{~S}$ ITS and phycocyanin operon sequences. - Phycologia 49: 361-372.

Earthwatch Institute (2006): Lesser Flamingos find new paradise at Kenya's Oloidien Lake. http://www. earthwatch.org/europe/newsroom/science/news-3lesserflamingos.html (accessed on 31.07.2012)

EDGAR, R.C. (2004): MUSCLE: multiple sequence alignment with high accuracy and high throughput. - Nucleic Acids Res. 32: 1792-1797.

GAO, K. \& MA, Z. (2008): Photosynthesis and growth of Arthrospira (Spirulina) platensis (Cyanophyta) in response to solar radiation, with special reference to its minor variant. - Environ. \& Experiment. Bot. 63: 123-129.

Harper, D.M.; Boar, R.R.; Everard, M. \& Hickley, P. (eds) (2002): Lake Naivasha, Kenya. - Developments in Hydrobiology 168: v-xii, 1-203.

Harper, D. M.; Childress, R. B.; Harper, M. M.; Boar, R. R.; Hickley, P. H.; Mills, S. C.; Otieno, N.; Drane, T.; Vareschi, E.; Nasirwa, O.; Mwatha, W. E.; Darlington, J. P. E. C. \& Escuté-Gasulla, X. (2003): Aquatic biodiversity and saline lakes: Lake Bogoria National Reserve, Kenya. - Hydrobiologia 500: 259-276.

Harper, D.M.; Morrison, E.H.J.; Macharia, M.M.; MaVUti, K.M. \& Upton, C. (2011): Lake Naivasha, Kenya: ecology, society and future. - Freshw. Rev. 4: 89114.

Harper, D.M., Muchane, M., Kimani, D.K. \& Mwinami, T. (2006): Thousands of Lesser Flamingos at Lake Naivasha? - Scopus 26, 8-10.

HepPerle, D. (2008): Align, Multisequence Alignment Editor ver. 05/2008 SequentiX - Digital DNA Processing, Klein Raden, Germany, www.sequentix.de.

JENKIN, P.M. (1957): The filter feeding and food of flamingos. (Phoenicopteri). - Philos. Trans. R. Soc. B 240: 401493.

Jungblut, A.D. \& Neilan, B.A. (2006): Molecular identification and evolution of the cyclic peptide hepatotoxins, microcystin and nodularin, synthetase genes in three orders of cyanobacteria. - Arch. Microbiol. 185: 107-114.

Kaggwa, M.N.; Gruber, M.; Oduor, S.O. \& Schagerl, M. (2012): A detailed time series assessment of the diet of Lesser Flamingos: further explanation for their itinerant behaviour. - Hydrobiologia 710: 83-93.

KalfF, J. \& Watson, S. (1986): Phytoplankton and its dynamics in two tropical lakes: a tropical and temperate zone comparison. - Hydrobiologia 138: $161-176$

KrienitZ, L. \& Kotut, K. (2010): Fluctuating algal food populations and the occurrence of Lesser Flamingos (Phoeniconaias minor) in three Kenyan Rift Valley lakes. - J. Phycol. 46: 1088-1096.

KrienitZ, L. \& WirTh, M. (2006): The high content of polyunsaturated fatty acids in Nannochloropsis limnetica (Eustigmatophyceae) and its implication for food web interactions, freshwater aquaculture and biotechnology. - Limnologica 36: 204-210.

Krienitz, L.; Ballot, A.; Kotut, K.; Wiegand, C.; Pütz, S.; Metcalf, J. S.; Codd, G.A. \& Pflugmacher, S. (2003): Contribution of hot spring cyanobacteria to the mysterious deaths of Lesser Flamingos at Lake Bogoria, Kenya. - FEMS Microbiol. Ecol. 1437: 141-148.

Krienitz, L.; Dadheech, P.K. \& Kotut, K. (2013): Mass developments of the cyanobacteria Anabaenopsis and Cyanospira (Nostocales) in the soda lakes of Kenya: ecological and systematic implications. Hydrobiologia 703: 79-93.

Maina, C. \& Kyungu, S. (eds.) (2009): The African Waterfowl Census. - Museum News, March-June 2009, 8.

MELACK, J.M. (1979): Photosynthesis and growth of Spirulina platensis (Cyanophyta) in an equatorial lake (Lake Simbi, Kenya). - Limnol. Oceanogr. 24: 753-760.

Nasirwa, O.; Owino, A.; Muchai, M. \& Ndang'Ang'A, K. (2007): Assessing trends in waterbird numbers in major Kenyan wetland sites (1991-2004). - Ostrich 78: 551-561.

Neilan, B.A.; Dittmann, E.; Rouhiainen, L.; Bass, A.; Schaub, V.; Sivonen, K. \& Börner, T. (1999): Nonribosomal peptide synthesis and toxigenicity of cyanobacteria. - J. Bacteriol. 181: 4089-4097.

Opticount (2008): - http://science.do-mix.de/software opticount.php

Owino, A.; Oyugi, J.O.; Nasirwa, O.O. \& Bennun, L.A. (2001): Patterns of variation in waterbird numbers on four Rift Valley lakes in Kenya. - Hydrobiologia 458: 45-53.

Rantala-Ylinen, A.; Kana, S.; Wang, H.; Rouhiainen, L.; 
Wahlsten, M.; Rizzi, E.; Berg, K.; Gugger, M. \& Sivonen, K. (2011): Anatoxin-a synthetase gene cluster of the cyanobacterium Anabaena sp. strain 37 and molecular methods to detect potential producers. - Appl. Environ. Microb. 77: 7271-7278.

Rich, F. (1932): Reports on the Percy Sladen Expedition to some Rift Valley Lakes in Kenya in 1929. - IV. Phytoplankton from the Rift Valley Lakes in Kenya. 233-262. - Ann. Magaz. Nat. Hist., ser. 10, 10: 233262.

Schagerl, M. \& Oduor, S.O. (2008): Phytoplankton community relationship to environmental variables in three Kenyan Rift Valley saline-alkaline lakes. Marin. Freshw. Res. 59:125-36.

STANDARD Media (2012): Some of the 1.5 million flamingoes fly around Lake Oloidien. http://www.standardmedia. co.ke/?id=2000027095\&cid=468\&story

Tamura, K.; Peterson, D.; Peterson, N.; Stecher, G.; Nei, M. \& Kumar, S. (2011): MEGA5: Molecular evolutionary lenetics lnalysis using laximum likelihood, evolutionary distance, and maximum parsimony methods. - Mol. Biol. Evol. 28: 27312739.

Tuite, C. H. (1981): Standing crop densities and distribution of Spirulina and benthic diatoms in East African alkaline saline lakes. - Freshw. Biol. 11: 345-360.

Tuite, C. H. (2000): The distribution and density of Lesser Flamingos in East Africa in relation to food availability and productivity. - Waterbirds (Spec. Publ.) 23: 52-63.

UtermöHL, H. (1958): Zur Vervollkommnung der quantitativen Phytoplankton-Methodik. - Mitt. Int. Verein. Limnol. 9: 1-38.
VARESCHI, E. (1978): The ecology of Lake Nakuru (Kenya) I. Abundance and feeding of the Lesser Flamingo. Oecologia 32:11-35.

VARESCHI, E. (1982): The ecology of Lake Nakuru (Kenya) III. Abiotic factors and primary production. Oecologia 55:81-101.

VARESChI, E. \& JACOBS, J. (1985): The ecology of Lake Nakuru VI. Synopsis of production and energy flow.

- Oecologia 65:412-24.

Verschuren, D.; Cocquyt, C.; Tibby, J.; Roberts, C.N. \& LeAVITT, P.R. (1999): Long-term dynamics of algal and invertebrate communities in a small, fluctuating tropical soda lake. - Limnol. Oceanogr. 44: 12161231.

Verschuren, D.; Tibby, J.; SAbBe, K. \& Roberts, N. (2000): Effects of depth, salinity, and substrate on the invertebrate community of a fluctuating tropical lake. - Ecology 81: 164-182.

VonshaK, A. (1997): Spirulina: Growth, physiology and biochemistry. - In: VonshaK, A. (ed.): Spirulina platensis (Arthrospira) physiology, cell biology and biotechnology. - pp. 43-65, Taylor \& Francis, London, UK.

VonshaK, A. \& Richmond, A. (1988): Mass production of the blue-green algae Spirulina, an overview. - Biomass 15: 233-247.

Vonshak, A.; Guy, R. \& Guy, M. (1988): The response of the filamentous cyanobacterium Spirulina platensis to salt stress. - Arch. Microbiol. 150: 417-420.

(C) Czech Phycological Society (2013)

Received January 6, 2013

Accepted April 28, 2013 